\title{
APPLICATION OF SURFACE LAYER INOCULATION PROCESSES TO SOLID SOLUTION-STRENGTHENED DUCTILE CAST IRON
}

\author{
Daniel Franzen and Andreas Bührig-Polaczek \\ Foundry-Institute, RWTH Aachen University, Intzestrasse 5, 52072 Aachen, Germany \\ Konrad Weiß \\ RWP GmbH, Bundesstraße 77, 52159 Roetgen, Germany \\ Joachim Gundlach \\ Grunewald GmbH and Co KG, Biemenhorster Weg 19, 46395 Bocholt, Germany
}

Copyright (c) 2020 The Author(s)

https://doi.org/10.1007/s40962-020-00406-5

\begin{abstract}
Within the present investigations, an in-mould inoculation method for ductile cast iron with elevated silicon contents was developed. The inoculation process takes place at the interface between the mould's surface and the melt. The application of a mould wall inoculation process allows inoculation at the latest possible point in time, which means high efficiency due to reduced fading effects. For this purpose, various inoculant suspensions are produced, containing inoculants in different amounts and grain fractions. The inoculant is applied to the surface of a PEP SET ${ }^{T M}$-bonded moulding material by means of an airpressurized spraying pistol. The specimen geometry used in the tests is a 5-stepped wedge, which represents wall

thicknesses in the range of 5-40 mm. For a total of 8 castings, inoculant fractions in the spectrum of 0-25 and 0-45 $\mu \mathrm{m}$ are used to produce the solid solution-strengthened grade EN-GJS-500-14 that is specified in the European standard EN 1563. Metallographic investigations show that a complete solidification according to the stable system can be adjusted in the investigated wall thicknesses by inoculation with grain fractions of 0-25 $\mu \mathrm{m}$.

Keywords: cast iron, ductile cast iron, solid solution strengthening, inoculation, surface layer metallurgy, mould wall inoculation

\section{Introduction}

Modern cast iron grades of solid solution-strengthened ductile cast iron were incorporated into the European Standard EN 1563 in 2012. These are primarily characterized by their elevated silicon content, ranging from 3.2 to $4.3 \mathrm{wt} . \%$ Si. Björkegren et al. ${ }^{1}$ showed that an increased silicon content leads to a fully ferritic matrix, which results in both improved machinability and very good static mechanical properties. According to Löblich, ${ }^{2}$ this is due to a more homogenous hardness distribution within the matrix. Furthermore, this alloy concept results in a widening of the interval between metastable and stable eutectic temperature. For this reason, the tendency to metastable eutectic solidification and the formation of cementite is significantly reduced. By alloying elevated

silicon contents from 3.2 to 4.3 wt. $\%$, significantly higher elongations can be achieved at the same tensile strength. In particular, Björkegren et al. ${ }^{3}$ showed that by alloying with 3.74 wt.\% Si elongations at fracture of $14 \%$ can be achieved at a set tensile strength of $500 \mathrm{MPa}$. Compared to conventionally ferritic-pearlitic cast iron grades, this means an increase in elongation at fracture of $100 \%$ without loss of strength. The specifications for the material grade EN-GJS-500-14 according to the European Standard EN 1563 are given in Table $1 .{ }^{4}$ Weiß et al. ${ }^{5}$ point out that due to alloying with alternative solid solution strengthening elements such as aluminium and nickel, the mechanical properties of these alloys can be further increased. Grades of high-silicon ductile cast iron are therefore particularly qualified for the use in higher loaded components and lightweight applications. Consequently, high-silicon
\end{abstract}


Table 1. Mechanical Properties Measured on Test Pieces Machined from Cast Sample for Solid Solution-Strengthened Ferritic Grades, EN-GJS-500-14, According to Ref. 4

\begin{tabular}{llll}
\hline Relevant wall thickness $(\mathrm{mm})$ & Yield strength (YS) at 0.2\% (MPa) & Ultimate tensile strength (UTS) (MPa) & Elongation at fracture (\%) \\
\hline$t<30$ & 400 & 500 & 14 \\
$30<t<60$ & 390 & 480 & 12 \\
$60<t$ & To be agreed upon between the manufacturer and the purchaser \\
\hline
\end{tabular}

ductile iron grades are assumed to be specifically suitable for the production of components with thin wall thicknesses.

Due to high undercooling in the production of castings with thin wall thicknesses, inoculation is an important metallurgical process step in order to ensure a stable solidification. Pearce captures the effect of the inoculation in his paper: by adding nuclei to the melt, the undercooling that is necessary for the precipitation of graphite is minimized. ${ }^{6}$ Consequently, the heterogeneous nucleation of the graphite during eutectic solidification is promoted, which allows formation of a carbide-free microstructure. During inoculation, mainly iron-silicon (FeSi)-compounds are immersed into the melt that shift the local thermodynamic equilibrium in a two-phase region of austenite and graphite. Lekakh et al. ${ }^{7}$ state that the local silicon content in the direct vicinity of graphite nuclei rises up to about 6 wt.\%. Consequently, the precipitation of graphite clusters is promoted in relevant temperature ranges from about 1300 to $1500{ }^{\circ} \mathrm{C}$.

According to Stefanescu et al., ${ }^{8}$ the carbon precipitating as graphite nodules during stable eutectic solidification is rapidly surrounded by a closed austenitic halo due to carbon depletion in the vicinity of the nuclei. As the solidification progresses, decoupled growth takes place, since the graphite is not in direct contact with the remaining liquid. Therefore, the carbon must diffuse through the solidified austenite halo. This leads to a significantly lower growth rate of the eutectic compared to cast iron with lamellar graphite. Therefore, under the same cooling conditions, a higher nucleus density is required in spheroidal graphite cast irons to ensure complete solidification according to the stable $\mathrm{Fe}-\mathrm{C}$ system.

On the one hand, it must be ensured that the inoculant has sufficient time to dissolve, which is also referred to as incubation time. ${ }^{9}$ On the other hand, inoculation must be sufficiently effective. Pearce claims in his paper that it is generally known that the inoculation effect decreases over time, which is known as fading effect. ${ }^{6}$ In order to increase the efficiency of the inoculation process and thus to ensure maximum economic benefits, the aim should be to inoculate at a time shortly before the beginning of eutectic solidification. Approaches of in-mould inoculation methods, like they were conducted by Labrecque et al. and Ojo et al. ${ }^{10,11}$ in which sintered pieces of inoculants are placed in the casting system, offer the possibility of reducing this fading effect. In order to further minimize the fading effect, in the present investigations the inoculation is not carried out in the casting system, but rather at the mould's cavity surface.

The interface between melt and moulding material offers the opportunity to modify the microstructure just before the start of the solidification. From studies that have been carried out in the past, it is known that the casting skin of ductile iron can be influenced by the selective modification of the interface melt-moulding material. In investigations carried out by Ivan et al., ${ }^{12}$ a casting skin containing degenerated graphite could be obtained in ductile iron by the selective use of a sulphur-containing coating. Studies by Kutz et al. ${ }^{13}$ showed that the iron matrix of the degenerated graphite layer could be specifically influenced by using a sulphur core coating without changing the graphite morphology of the casting skin at the same time. The use of coatings containing desulphurizing compounds such as $\mathrm{MgO}$, on the other hand, led to a reduction in graphite degeneration in the area of the casting skin. ${ }^{12,14}$ Boonmee et al. ${ }^{15}$ found that coatings containing ferrosilicon decrease the thickness of the casting skin, in particular in medium and high CE ductile irons, whereas graphitecontaining coatings lead to a significant reduction in the casting skin thickness, especially in low CE ductile irons. According to studies conducted by Qing et al., ${ }^{16}$ also parameters such as the pouring temperature, the position of sulphur-modified core inserts within the mould and chilling effects have a significant effect on the graphite degeneration layer in ductile iron.

The approaches described above can be summarized as techniques of surface layer metallurgy which focus mainly on the modification of the casting skin. However, the method of an inoculation via the mould's surface aims at the holistic modification of the microstructure. Investigations carried out by Fischer et al. ${ }^{17}$ show that it is possible to successfully inoculate lamellar graphite cast iron using mould wall inoculation processes. In these studies, a complete stable eutectic solidification of a hypoeutectic lamellar graphite cast iron melt could be achieved in wall thicknesses ranging from 10 to $40 \mathrm{~mm}$. The authors studied various inoculant suspensions consisting of inoculants in different grain fractions and quantities, water and a 
Table 2. Chemical Composition, Element Concentrations in wt.\% ('Obtained from Thermal Analysis)

\begin{tabular}{llllllll}
\hline $\mathrm{C}^{\mathrm{a}}$ & $\mathrm{Si}$ & $\mathrm{Mn}$ & $\mathrm{P}$ & $\mathrm{S}$ & $\mathrm{Mg}$ & $\mathrm{Fe}$ & $\mathrm{CE}$ \\
\hline $3.0 \pm 0.2$ & $3.85 \pm 0.1$ & $0.11 \pm 0.001$ & $0.01 \pm 0.002$ & $0.006 \pm 0.001$ & $0.038 \pm 0.001$ & Balance & 4.29 \\
\hline
\end{tabular}

Table 3. Chemical Composition of the Inoculant Measured by EDX $\left.{ }^{a}\right]$ and Wet-Chemicals Analyses, Element Concentrations in wt.\%

\begin{tabular}{llllll}
\hline $\left.\mathrm{Si}^{[}{ }^{3}\right]$ & $\mathrm{Al}$ & $\mathrm{Ca}$ & $\mathrm{Bi}$ & $\mathrm{Ce}$ & $\mathrm{Fe}$ \\
\hline $69.3 \pm 4.0$ & $4.55 \pm 0.2$ & $1.05 \pm 0.05$ & $0.035 \pm 0.025$ & $0.06 \pm 0.01$ & Bal. \\
\hline
\end{tabular}

suspending agent and applied them to the surface of the mould. The investigated grain sizes of the inoculant ranging from $0-25$ to $0-45 \mu \mathrm{m}$ were used as secondary products that result from the production of conventional inoculants. Usually, these grain fractions are no longer used and are therefore available for low costs, which means high economic advantages. However, there have been no studies about the application of mould wall inoculation processes to modern grades of SGI. In order to close this current research gap, the inoculation method is applied to solid solution-strengthened nodular cast irons.

In order to apply mould wall inoculation techniques to high-silicon ductile cast iron, the grade EN-GJS-500-14 according to the European standard EN 1563 was produced in a total of two melts. The carbon equivalent (CE), calculated by Eqn. 1, was set to eutectic (4.3 wt.\%) composition. The average chemical composition of the melts is given in Table 2.

$C E=\% C+1 / 3 \% S i+1 / 3 \% P$

Eqn. 1

\section{Experimental Procedure}

An inoculant based on aluminium and calcium as the main nucleating elements was chosen. The inoculant's chemical composition measured by wet-chemical and electron microscopic analyses is given in Table 3 . In order to investigate the effect of different grain fractions and amounts of the inoculation agent, the powdered fractions that accrue during conventional production were classified by means of sieving and grinding. In this way, two different inoculant grain fractions $(0-25 \mu \mathrm{m}$ and $0-45 \mu \mathrm{m})$ were produced. The morphology of the inoculant was then studied by using electron microscopic methods. Different inoculation suspensions consisting of water as the carrier medium, a suspension agent and grain-classified inoculant were then prepared. An overview of the investigated inoculant suspensions is given in Table 4. Based on the maximum mixability of the different inoculant grain sizes in the suspension, maximum inoculant contents for each suspension were chosen. The amount of the suspension agent was constantly held at $3 \mathrm{~g}$ for each of the suspensions. The total weight of inoculant suspension that was
Table 4. Overview of the Investigated Inoculation Suspensions

\begin{tabular}{lllll}
\hline No. & $\begin{array}{l}\text { Inoculant } \\
\text { grain size } \\
(\mu \mathrm{m})\end{array}$ & $\begin{array}{l}\text { Amount of } \\
\text { water in } \\
\text { suspension } \\
(\mathrm{g})\end{array}$ & $\begin{array}{l}\text { Percentage } \\
\text { of inoculant } \\
(\mathrm{wt} . \%)\end{array}$ & $\begin{array}{l}\text { Total sprayed } \\
\text { amount of } \\
\text { inoculant } \\
\text { suspension }(\mathrm{g})\end{array}$ \\
\hline 1 & $0-25$ & 100 & 70 & $2.28 \pm 0.22$ \\
2 & & & 80 & $2.47 \pm 0.32$ \\
3 & & 90 & $2.95 \pm 0.43$ \\
4 & $0-45$ & & 60 & $2.84 \pm 0.49$ \\
5 & & & 70 & $3.23 \pm 0.55$ \\
\hline
\end{tabular}

sprayed onto the mould depends on the inoculant grain size and varies from 2.28 to $3.23 \mathrm{~g}$. After mixing of the components using a motorized mixer for about $2 \mathrm{~min}$, the different inoculant suspensions were sprayed manually onto the mould's cavity surface by using an air-pressurized spraying pistol. In order to verify the quantity of the sprayed inoculant, spray tests were carried out on standardized paper samples with a defined area before the casting tests. By weighing the samples, the sprayed amount of inoculant changing in the different grain fractions and varying inoculant amounts could be determined. By setting constant parameters such as a spraying distance of $20 \mathrm{~cm}$, an angle of about $45^{\circ}$ as well as the spraying time and a spraying pressure of $1.8 \mathrm{bar}$, comparability among the trials was ensured. As a casting geometry, two 5-stepped $(5 \mathrm{~mm}, 10 \mathrm{~mm}, 20 \mathrm{~mm}, 30 \mathrm{~mm}$ and $40 \mathrm{~mm}$ ) wedges with a constant width of $50 \mathrm{~mm}$ and length of $250 \mathrm{~mm}$ were cast per sand mould, as shown in Figure 1. A completely uninoculated step wedge was produced, which served as a reference for assessing the original nucleus level in the melt. The moulding material used for building the sand moulds consisted of PEP SET ${ }^{\mathrm{TM}}$-bonded silica sand with 0.8 wt. $\%$ of each binder and hardener.

After drying of the inoculation suspension, the moulds were prepared for casting. Raw materials consisting of return cast iron, pure iron and ferrosilicon $(\mathrm{FeSi})$ were prepared and melted in a 50-kg medium-frequency induction furnace using a graphite crucible. This was followed 
by overheating to $1500{ }^{\circ} \mathrm{C}$ and holding this temperature for about five minutes in order to remove impurities from the melt. After deslagging of the melt, magnesium treatment with a cerium-free magnesium master alloy at about $1430{ }^{\circ} \mathrm{C}$ was performed using a plunger. A cerium-free magnesium master alloy was chosen in order to prevent the formation of chunky graphite. Four moulds with different inoculation settings were cast per heat at a pouring temperature of $1370-1350{ }^{\circ} \mathrm{C}$. The results were generated from a total of two melts which are subjected to process deviations and can therefore have an influence on the investigated microstructural parameters. Since, however, charging material from one batch with a constant chemical composition was used and the furnace processing was controlled very precisely, it can be assumed that the

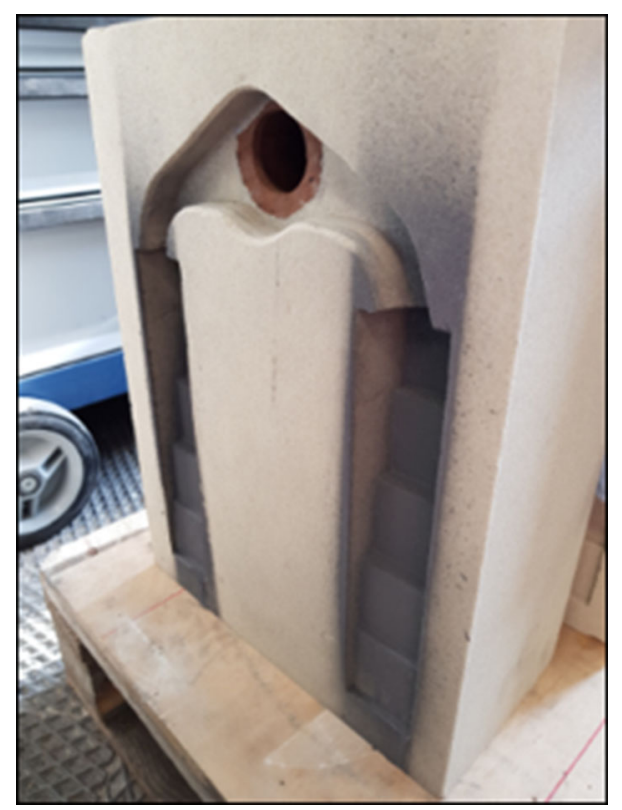

Figure 1. PEP SET-bonded and mould wall-inoculated sand mould with cavities for two step wedges. process variations were minimized and the basic nucleus level of the melts can be regarded as constant.

From the step wedge produced, one metallographic specimen per step was separated from the middle of each section by using a water-cooled cut-off saw; see Figure 2. After subsequent embedding of the samples, metallographic preparation was conducted by grinding with 180, 320, 500 and 1000 grid $\mathrm{SiC}$ paper and polishing by using diamond suspensions with particles of 9,3 and $0.25 \mu \mathrm{m}$. The samples were then studied with regard to their microstructure using light microscopic investigations. Images of $100 \mathrm{x}$ magnification were then analysed via automated image analysis using the software AxioVision. Besides studies regarding the graphite phase (nodule count and nodularity) in different wall thicknesses and at varying inoculation settings, Nital etchings were carried out in order to reveal the pearlite fraction for selected specimens. For the evaluation of the graphite phase, particles with a particle area of smaller than $20 \mu \mathrm{m}$ were not taken into account during automated image analysis.

\section{Results and Discussion}

\section{Inoculant Analysis}

Figure 3 shows the morphology of the two inoculant grain fractions that were studied. Due to milling of the inoculant grain size of $0-25 \mu \mathrm{m}$, the morphology of the inoculant seems to be finer and rounded, whereas the morphology of the $0-45 \mu \mathrm{m}$ inoculant is flakier.

\section{Graphite Analysis}

Figure 4 shows the formation of the graphite phase determined by means of light microscopic images in the uninoculated state and for inoculations with the grain size

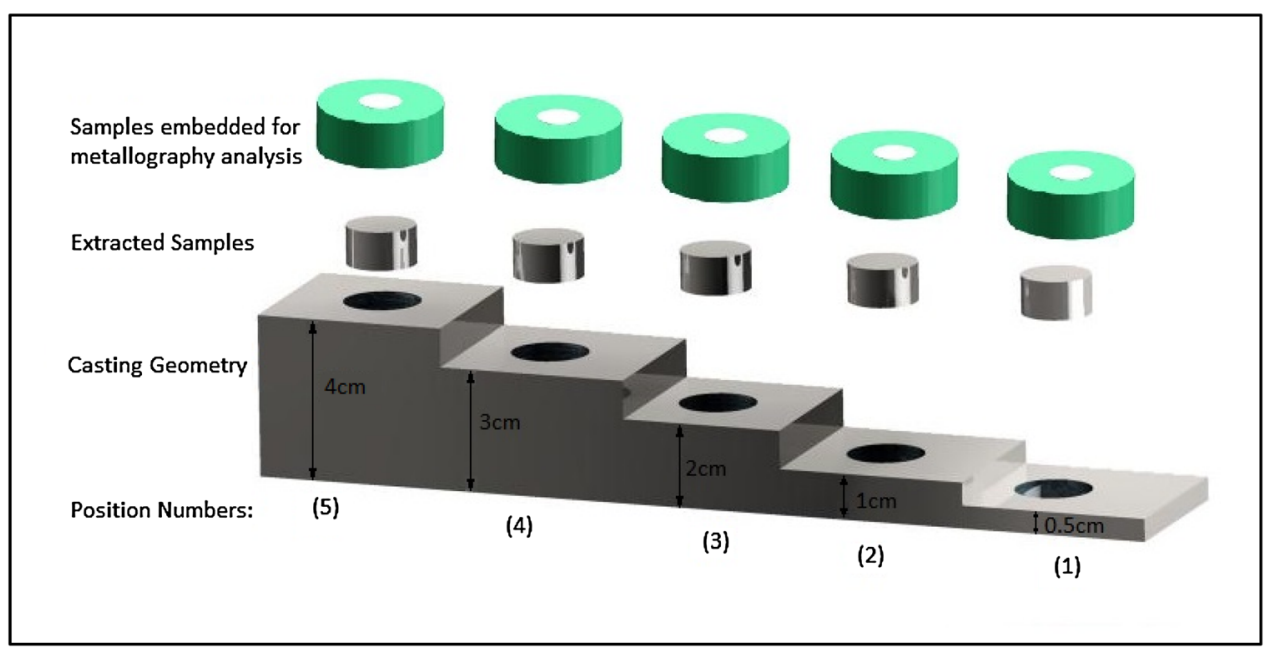

Figure 2. Location of metallographic specimen in the middle of each step. 
(a)

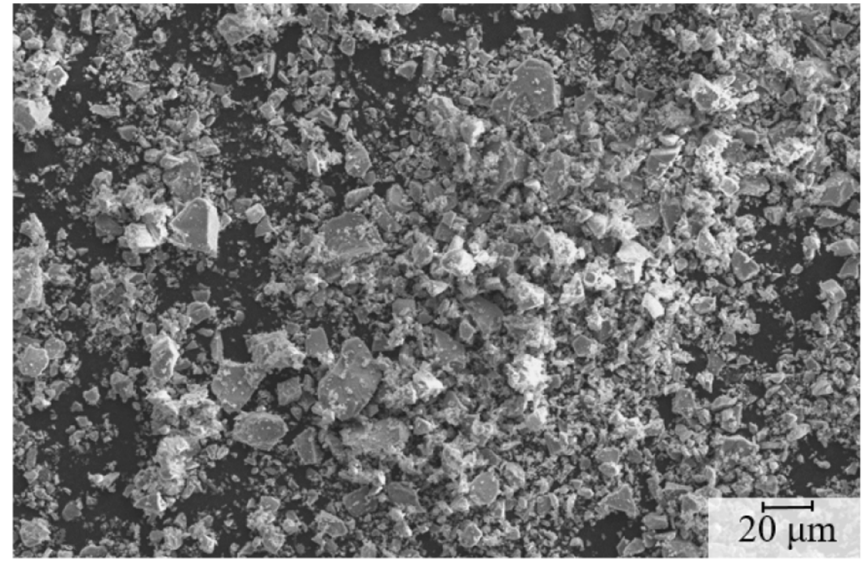

(b)

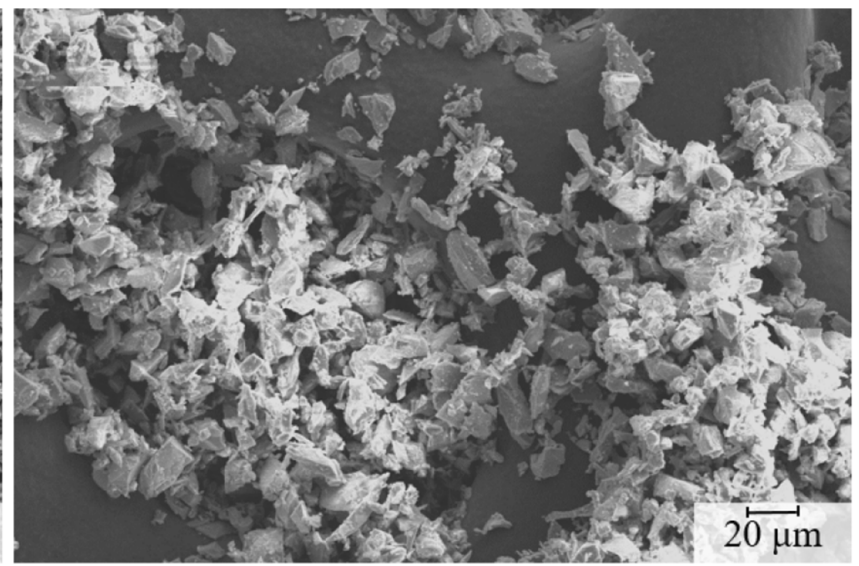

Figure 3. Image of the investigated inoculant grain sizes by scanning electron microscopy at 1000x magnification, (a) 0-25 $\mu \mathrm{m}$ and (b) $0-45 \mu \mathrm{m}$.

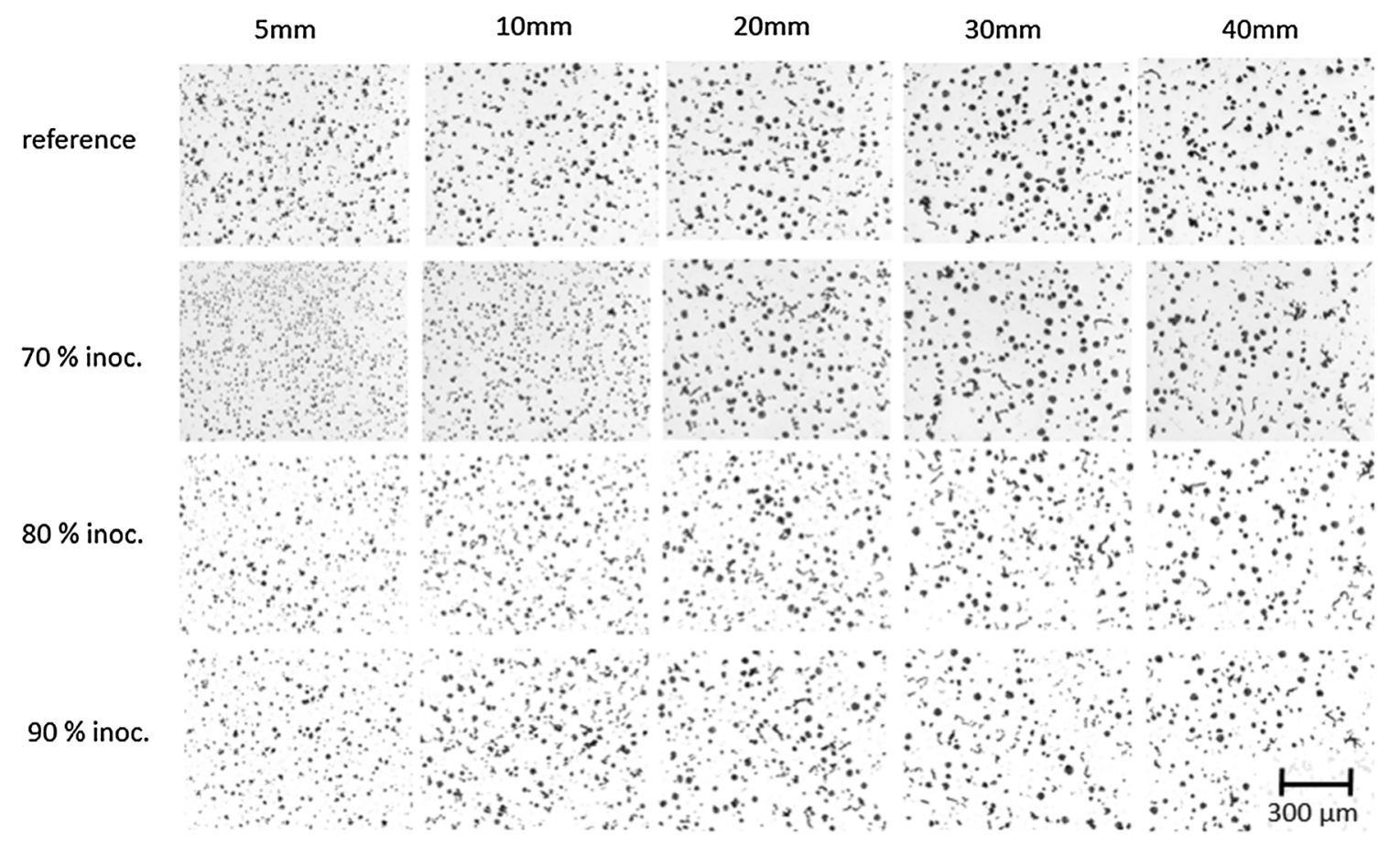

\section{Figure 4. Representative images of the graphite phase in samples inoculated with 0-25 $\mu \mathrm{m}$ inoculant for different amounts of inoculant and wall thicknesses.}

of $0-25 \mu \mathrm{m}$ for the studied wall thicknesses $5-40 \mathrm{~mm}$. The analysis of the unetched samples shows that the size of the precipitated graphite nodules tends to be larger in the uninoculated sample than in mould wall-inoculated samples. This indicates a lower inoculation level in the reference sample, which results in higher amounts of carbon diffusing to each nucleus.

The highest nodule count can visually be achieved by inoculation with $70 \%$ in the grain size of $0-25 \mu \mathrm{m}$ in suspension, especially in thin wall thicknesses (5 and $10 \mathrm{~mm}$ ), which is due to a higher undercooling during solidification. If the inoculant content is increased to 80 or
$90 \%$, a lower nodule count can be determined. Due to a higher inoculant content, a layer of undissolved inoculant emerges on the surface of the casting, so that an incomplete dissolution of the inoculant and thus an insufficient inoculation effect occurs during mould filling, as indicated in Figure 5. In the industrial process, this layer of undissolved inoculant would be problematic during unpacking, as the residues accumulate in the operating sand. This would therefore have to be reclaimed with great effort. In addition, due to the high iron content of the inoculant, the undissolved inoculant acts as a chill layer which increases the actual cooling rate and thus promotes the formation of 


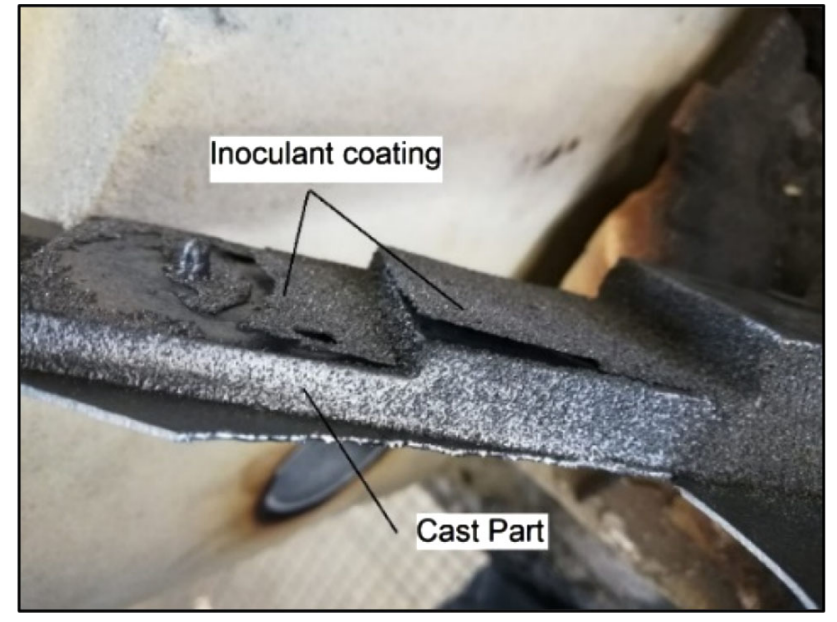

Figure 5. Layer of undissolved inoculant on the casting surface at an inoculant content of at least $80 \%$.

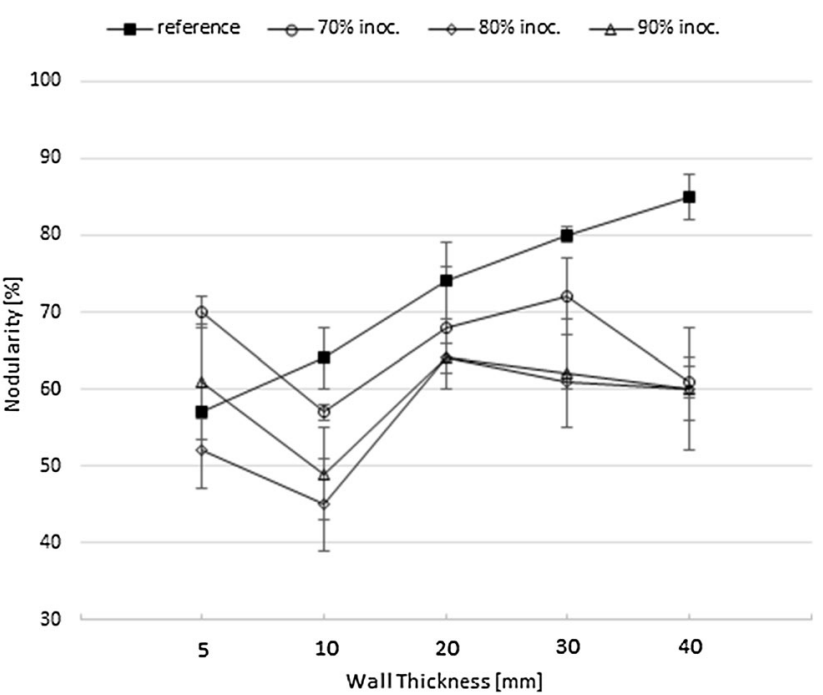

Figure 6. Nodularity in samples inoculated with 0-25 $\mu \mathrm{m}$ inoculant examined by automated image analysis.

ledeburite and pearlite. An effective inoculation in these cases is therefore excluded.

Figures 6 and 7 show the graphite parameters nodularity and nodule count for the reference sample and the samples inoculated with $0-25 \mu \mathrm{m}$ inoculant suspensions. When considering the nodularity, the trend towards higher nodularity at lower cooling rates can be observed in all test series, i.e. independent of the inoculant grain sizes that are studied. This clearly does not correspond to the expectations, since a lower nodule count, as it occurs in elevated wall thicknesses, is associated with a lower nodularity at a constant graphite content. Measurements of the residual magnesium content in the individual wall thicknesses have not shown any differences so far. For this reason, this phenomenon is attributed to the cut-off value for the graphite particle area that was set to $20 \mu \mathrm{m}$ during automated image analysis.

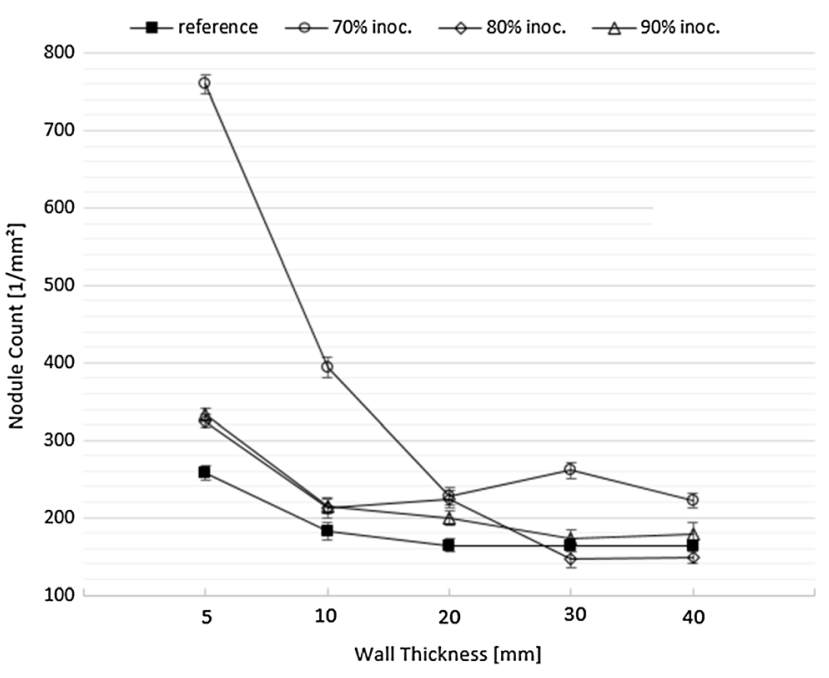

Figure 7. Nodule count in samples inoculated with 0-25 $\mu \mathrm{m}$ inoculant examined by automated image analysis.

Due to the incomplete dissolution of the inoculant at an inoculant content of 80 or $90 \%$, the nodule count in all wall thicknesses is only increased by about 50-70 nodules per $\mathrm{mm}^{2}$ compared to the reference samples. The inoculation with an inoculant content of $70 \%$ can be described as very successful due to a significant increase in the nodule count by about 500 nodules per $\mathrm{mm}^{2}$ compared to the reference sample. This effect is particularly significant at higher cooling rates. However, if the wall thickness is at least $20 \mathrm{~mm}$, this effect cannot be observed. Due to lower cooling rates in these wall thicknesses, a stronger fading effect occurs, which reduces the inoculation effectiveness. Further investigations will focus on lower inoculant contents of this grain size in order to define a critical inoculant for the production of fully grey solidified microstructure with high nodule counts.

Figure 8 compares the microstructure of the reference and of samples inoculated with $0-45 \mu \mathrm{m}$ grain size inoculant. From the images, it can be seen qualitatively that an increase in the nodule count can also be achieved by using the grain size $0-45 \mu \mathrm{m}$. The use of $60 \%$ inoculant in suspension tends to result in a higher nodule count compared to the uninoculated state. The nodule count decreases in all series of studies with increasing wall thickness which is attributed to lower cooling rates. Due to lower cooling rates, the undercooling during eutectic solidification is decreased, which means more time for the carbon to diffuse towards graphite nuclei. At a constant amount of carbon in the melt, the formation of less graphite nodules is the result. In contrast, by using mould wall inoculations smaller nodule sizes seem to be achieved, which is due to lower undercoolings during eutectic solidification. In smaller wall thicknesses, the inoculation has a positive effect on the nodule count, which indicates a cooling rate that is high enough to prevent fading of the inoculant in this grain fraction. 


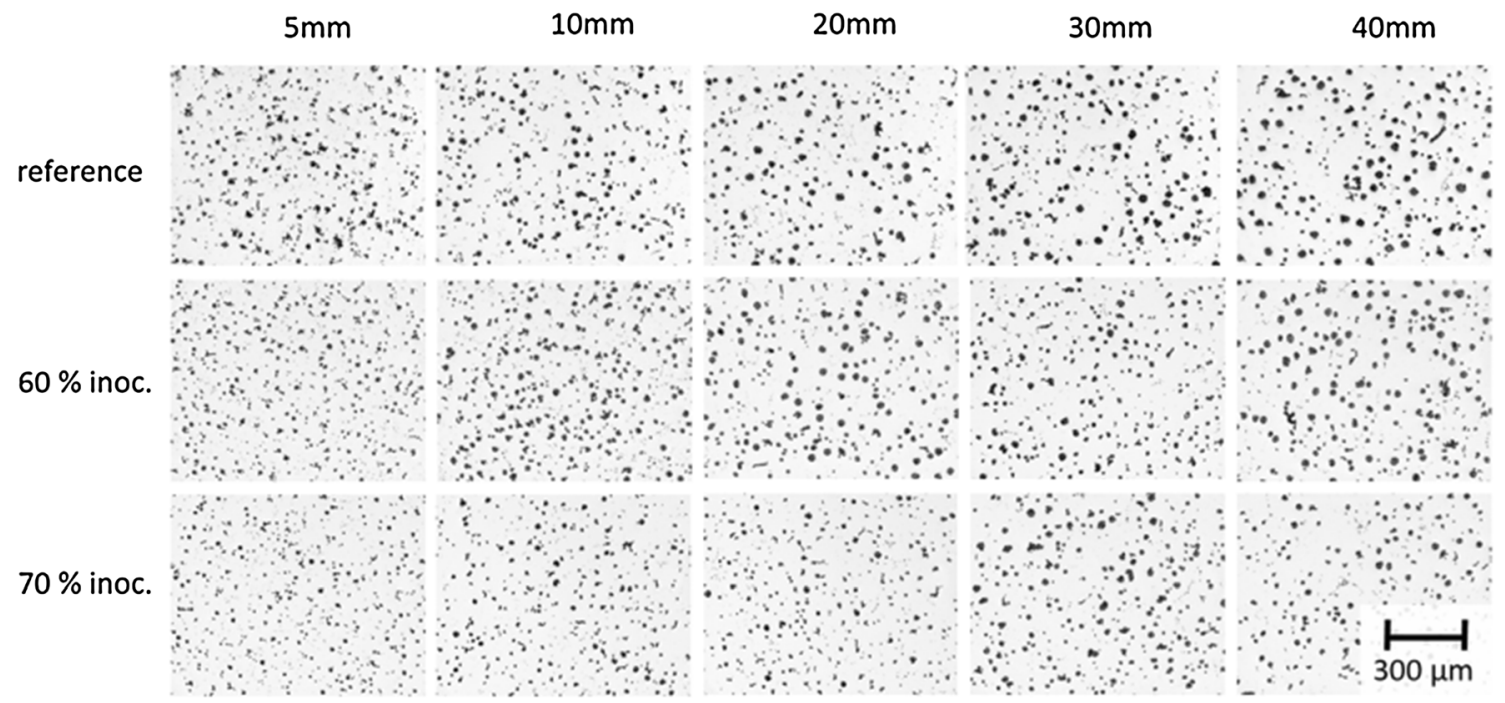

Figure 8. Representative images of the graphite phase in samples inoculated with $0-45 \mu \mathrm{m}$ inoculant for different amounts of inoculant and wall thicknesses.

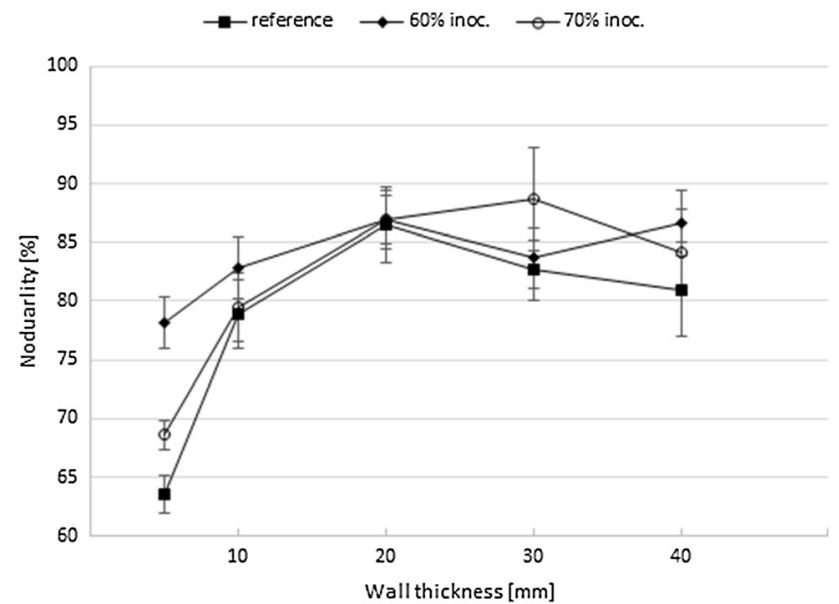

Figure 9. Nodularity in samples inoculated with 0-45 $\mu \mathrm{m}$ inoculant examined by automated image analysis.

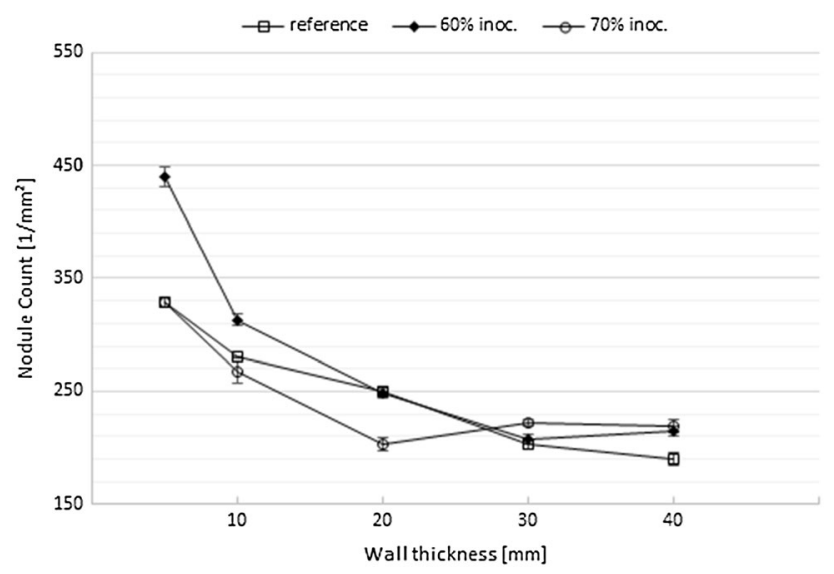

Figure 10. Nodule count in samples inoculated with 0-45 $\mu \mathrm{m}$ inoculant examined by automated image analysis.
Figures 9 and 10 show the graphite parameters nodularity and nodule count for samples inoculated with the inoculant grain size $0-45 \mu \mathrm{m}$. The trend towards lower nodularity in thin wall thicknesses is also evident in this test series. In uninoculated samples, the nodularity is lowest at $63 \%$ in $5 \mathrm{~mm}$ and increases to $87 \%$ in $20 \mathrm{~mm}$. By inoculation with the grain size $0-45 \mu \mathrm{m}$, a higher nodularity particularly in thin wall thicknesses can be achieved. In $5 \mathrm{~mm}$, a nodularity of approx. $79 \%$ is obtained at an inoculation with $60 \%$ inoculant in suspension, which remains widely constant over the investigated range of wall thicknesses. By using 70\% inoculant in the applied suspension, however, no significant increase in nodularity can be achieved. Compared to inoculations with the $0-25 \mu \mathrm{m}$ grain size fraction, a higher nodularity tends to be achieved by using inoculants with $0-45 \mu \mathrm{m}$ grain size, independent of the wall thickness that is investigated. The nodule count in the uninoculated reference sample is highest at approx. 320 1/ $\mathrm{mm}^{2}$ at a wall thickness of $5 \mathrm{~mm}$ and decreases to approx. $1901 / \mathrm{mm}^{2}$ when the wall thickness is increased to $40 \mathrm{~mm}$. An inoculation with $70 \%$ inoculant of the $0-45 \mu \mathrm{m}$ grain size does not increase the nodule count. By inoculation with $60 \%$ inoculant in suspension, an increase in the nodule count to approx. $4401 / \mathrm{mm}^{2}$ can be observed, especially in $5 \mathrm{~mm}$. The results obtained from the graphite analysis are summarized and compared with each other in Figure 11.

\section{Pearlite Analysis}

Figure 12 comparatively shows the formation of the matrix phase in different wall thicknesses for the inoculant grain sizes $0-25$ and $0-45 \mu \mathrm{m}$. While the reference sample at a wall thickness of $5 \mathrm{~mm}$ shows significant amounts of white solidified areas, all samples inoculated with a grain size of $0-25 \mu \mathrm{m}$ are fully grey solidified. This confirms the results of Fischer et al. ${ }^{17}$ and further provides the indication that a 

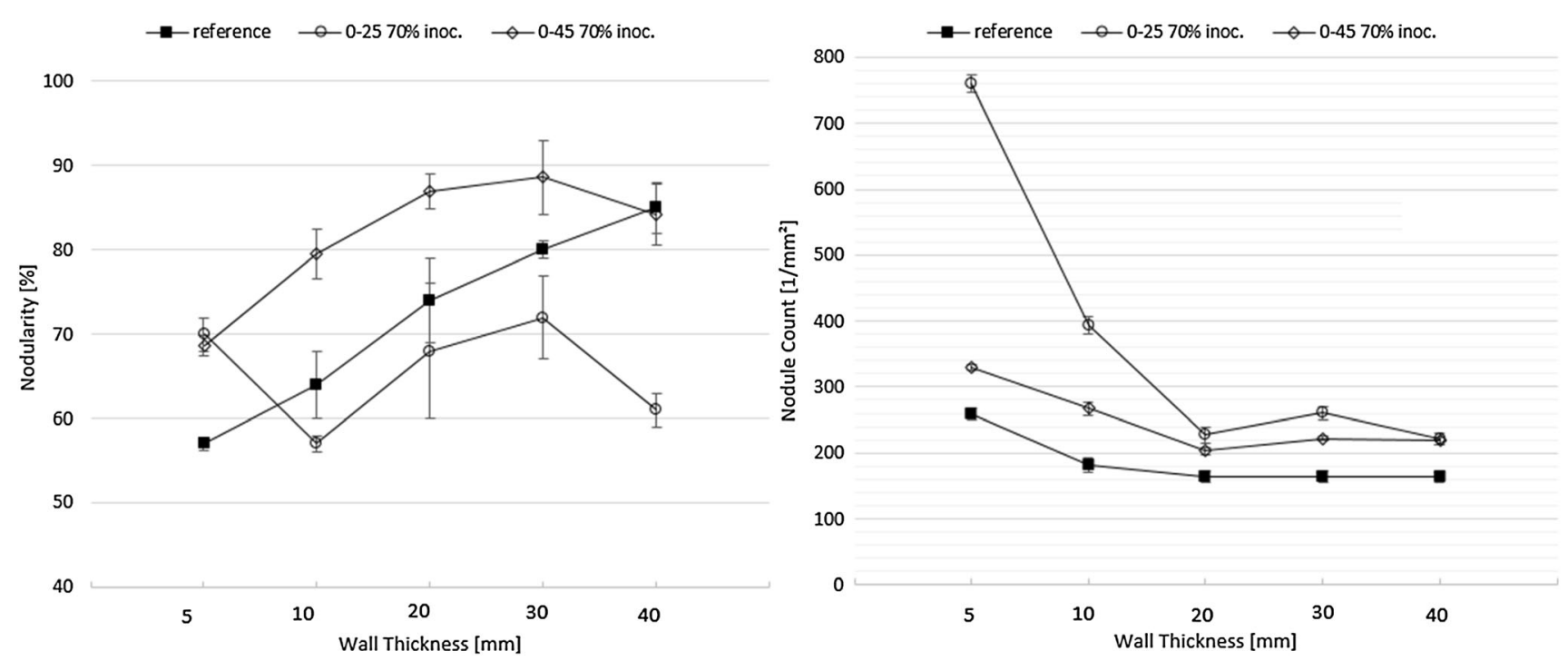

100

$\begin{array}{lcccc}0 & & & \\ & 10 & 20 & 30\end{array}$

Figure 11. Comparison of the nodularity (left) and the nodule count (right) of the reference and the inoculant grain sizes $0-25$ and $0-45 \mu \mathrm{m}$.

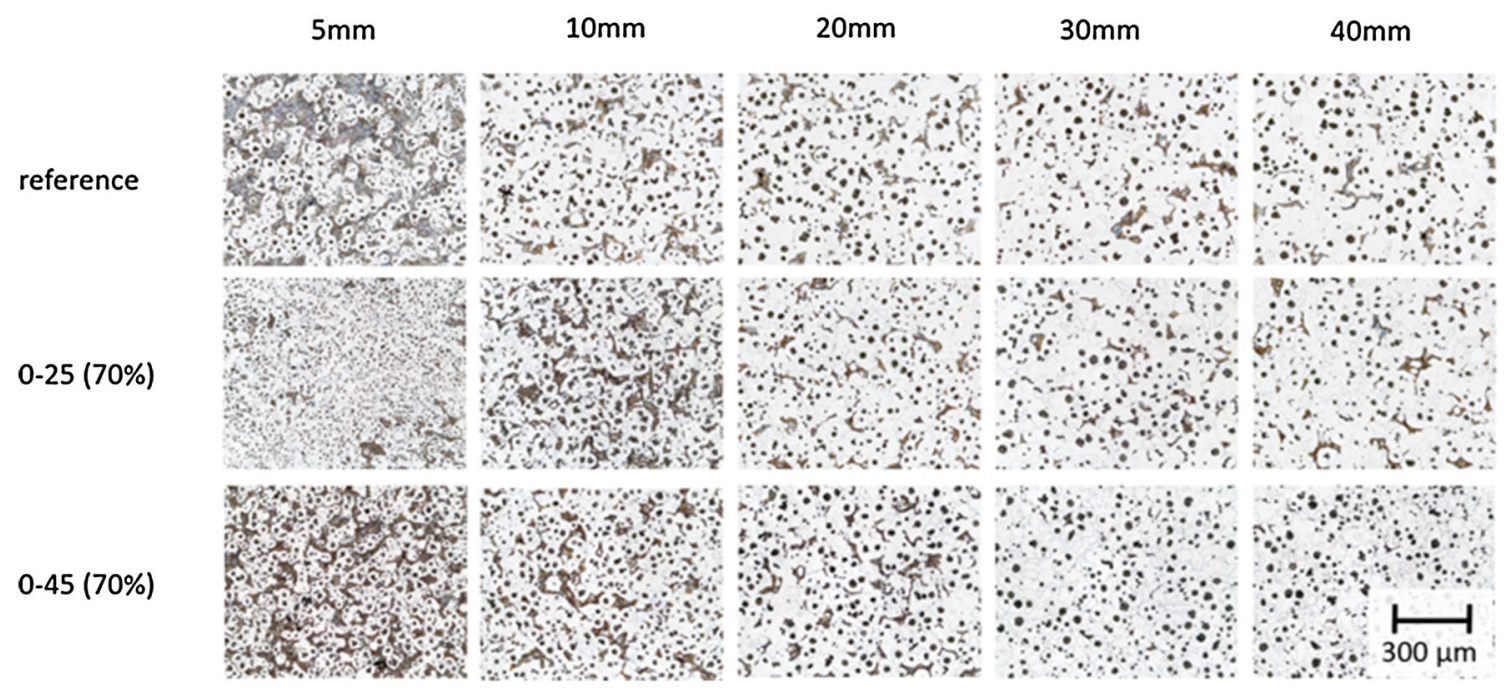

Figure 12. Representative images of the pearlite phase in samples inoculated with $70 \%$ inoculant of the inoculant grain sizes $0-25$ and 0-45 $\mu \mathrm{m}$ for different wall thicknesses at 100x magnification.

complete solidification according to the stable system is possible also for SGI and down to wall thicknesses of $5 \mathrm{~mm}$ when mould wall inoculation processes are applied. However, the microstructure of the $5 \mathrm{~mm}$ sample shows low amounts of metastable solidified areas. Therefore, inoculation with an inoculant grain size $0-45 \mu \mathrm{m}$ in $5 \mathrm{~mm}$ does not result in a complete stable eutectic solidification with the formation of graphite.

As indicated in Figure 13, an average pearlite content of about $48 \%$ is measured in $5 \mathrm{~mm}$ in the reference sample, which decreases to about $25 \%$ when the wall thickness is increased. Minimum pearlite contents of approx. $17 \%$ can be measured in a wall thickness of $5 \mathrm{~mm}$ when applying a mould wall inoculation with $70 \%$ of the grain size of
0-25 $\mu \mathrm{m}$ in suspension. This clearly correlates with the significant higher nodule count observed from the graphite analysis. The precipitation of many nodules during the eutectic solidification results in very short carbon diffusion paths. The formation of ferrite is a result of carbon depletion in the direct vicinity of the graphite nodules. A formation of pearlite is thus inhibited in these areas. If the inoculant content is increased to 80 or $90 \%$, no further reduction in the pearlite content can be observed. The reason for this is reduced inoculation effect due to insufficient dissolution of the inoculant. Additionally, the ferritizing effect of the silicon in the inoculant is eliminated, too. For this reason, further investigations will be focused on lower contents of inoculant with a grain size of $0-25 \mu \mathrm{m}$. 


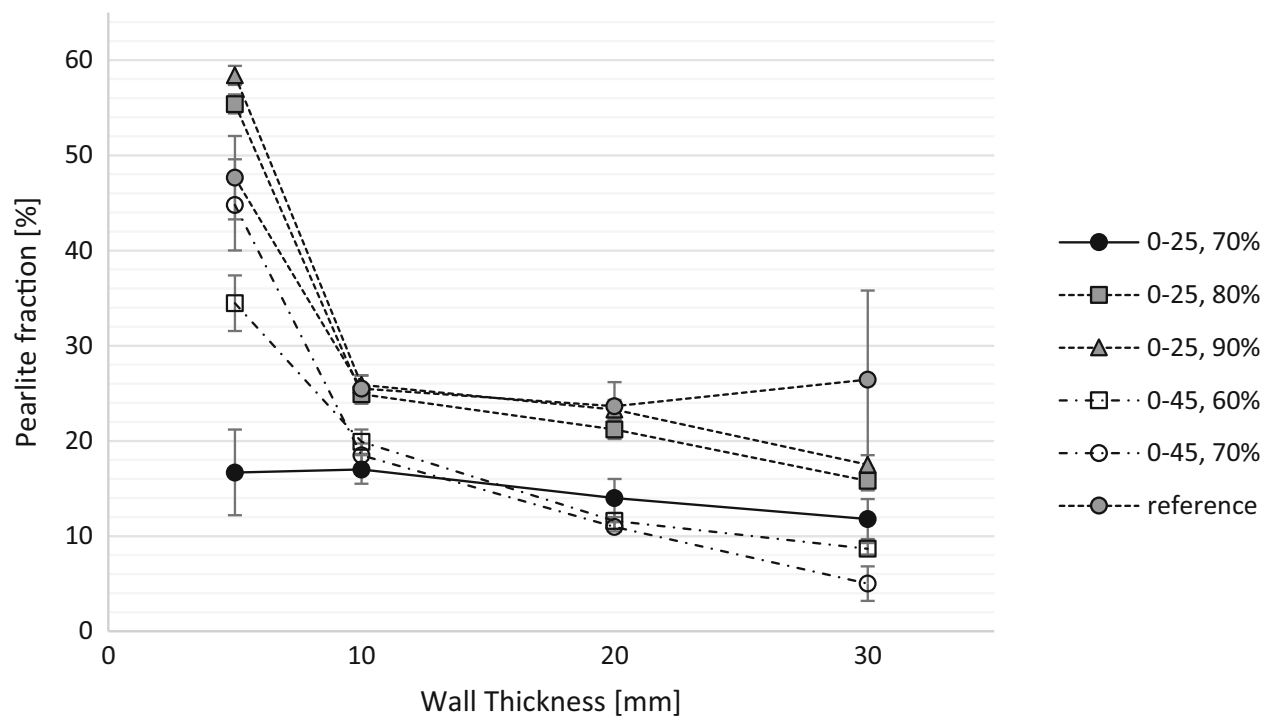

Figure 13. Analysis of the pearlite fraction for the inoculant grain sizes $0-25$ and 0-45 $\mathrm{\mu m}$ in different wall thicknesses.

By inoculation with the grain size $0-45 \mu \mathrm{m}$, the pearlite content can be reduced in all wall thicknesses compared to the uninoculated state. A pearlite content of approx. $34 \%$ is achieved by using $60 \%$ inoculant in suspension in $5 \mathrm{~mm}$. When the fraction of inoculant is increased to $70 \%$, however, no further decrease in the pearlite content is observed. In $10 \mathrm{~mm}$, minimum pearlite contents of about $19 \%$ can be achieved with both inoculant grain sizes. If the wall thickness is further increased, no difference in the pearlite content between the individual inoculations is detected. Due to the larger mean diameter of the inoculant particles in the $0-45 \mu \mathrm{m}$ grain fraction, a longer incubation time of the inoculant is required to provide a maximum inoculation effect. A maximum inoculation effect is therefore achieved at lower cooling rates, as they occur in wall thicknesses of 20 and $30 \mathrm{~mm}$. For this reason, the grain size $0-25 \mu \mathrm{m}$ is particularly suitable for wall thicknesses of 5 and $10 \mathrm{~mm}$, while larger grain fractions are to be preferred for elevated wall thicknesses in the range of $20-40 \mathrm{~mm}$.

According to the European standard EN 1563, a maximum pearlite content of 5\% is specified for high silicon grades of ductile iron. The adjustment of a maximum pearlite content of $5 \%$ could not be ensured in wall thicknesses below $30 \mathrm{~mm}$ by applying mould wall inoculation methods. Due to shorter incubation times, it is assumed that the grain size $0-25 \mu \mathrm{m}$ is ideally suited for the inoculation of melts in thinner sections of 5 and $10 \mathrm{~mm}$. A maximum inoculant content of $70 \%$ should be applied in order to obtain a complete dissolution of the inoculant at the investigated casting temperatures.

Based on the results observed, the inoculation method presented here is proposed to be a time- and thus costsaving process step for the production of conventional ferritic-pearlitic SGI, where higher pearlite contents are desired. In this context, the application of the inoculation methodology to lower wall thicknesses of $2 \mathrm{~mm}$ is intended in further studies. In addition, the application of this inoculation method to conventional coatings in the production of ductile iron offers the possibility of developing metallurgical coatings for critical parts of the mould. In this way, critical parts of the component can be treated prior to casting in order to obtain selective solidification of the melt.

\section{Conclusions}

Based on the results obtained from an innovative inoculation method via the mould wall for high-silicon ductile iron, the following aspects can be concluded.

- In wall thicknesses of down to $10 \mathrm{~mm}$, the application of mould wall inoculation processes leads to a fully stable solidification of high-silicon ductile iron.

- A mould wall inoculation with the inoculant's grain size of $0-25 \mu \mathrm{m}$ leads to a fully solidification according to the stable system in all investigated wall thicknesses. Mould wall inoculation processes with small inoculant grain sizes $(0-25 \mu \mathrm{m})$ are therefore ideally qualified for the production of thinner walled ductile iron $(5 \mathrm{~mm})$ castings.

- Maximum pearlite contents of 5\% according to the European Standard EN 1563 cannot be fulfilled due to higher cooling rates particularly in thin wall thicknesses.

- The development and application of mould wall inoculation processes provide to be a promising 
tool for the production of conventional ductile iron, where elevated pearlite is desired.

- The method of mould wall inoculation offers the possibility of transfer and application to metallurgical coatings in order to inoculate critical component areas (thin wall thicknesses) shortly before solidification.

Based on the results obtained in this study, it can be summarized that mould wall inoculations with a grain size of the inoculant of 0-25 $\mu \mathrm{m}$ represent a suitable metallurgical tool for reliably achieving stable solidification of high-silicon SGI in wall thicknesses of $5-40 \mathrm{~mm}$. It is therefore assumed that this innovative inoculation technique represents an appropriate method either as a single or additional inoculation step in order to produce components of high-silicon ductile iron even in lower wall thicknesses.

\section{Acknowledgements}

Open Access funding provided by Projekt DEAL. The authors gratefully acknowledge Wolfgang Geiger of ASK Chemicals for the supply of inoculants in appropriate grain fractions. Further special acknowledgements go to Ingo Braun for the support during the casting trials, Elke Schaberger-Zimmermann for her assistance during the metallographic preparation and finally Susanne Hemes for the support during the image analysis.

\section{Funding}

The presented results are derived from a cooperation project of Grunewald GmbH \& Co. KG, RWP GmbH and the Foundry Institute of RWTH Aachen, which was funded within the scope of the joint collaborative program "Central Innovation Programme SMEs" (ZIM), supported by the Federal Ministry for Economic Affairs and Energy, following a decision of the German Bundestag.

\section{Compliance with Ethical Standard}

Conflict of interest There is no conflict of interest.

Open Access This article is licensed under a Creative Commons Attribution 4.0 International License, which permits use, sharing, adaptation, distribution and reproduction in any medium or format, as long as you give appropriate credit to the original author(s) and the source, provide a link to the Creative Commons licence, and indicate if changes were made. The images or other third party material in this article are included in the article's Creative Commons licence, unless indicated otherwise in a credit line to the material. If material is not included in the article's Creative Commons licence and your intended use is not permitted by statutory regulation or exceeds the permitted use, you will need to obtain permission directly from the copyright holder. To view a copy of this licence, visit http://creativecommons. org/licenses/by/4.0/.

\section{REFERENCES}

1. L.-E. Björkegren. Ferritic ductile iron with higher silicon content. Swedish Foundry Association, Swerea SWECAST Report 941028, 1994.

2. H. Löblich. Schlussbericht zum IGF-Forschungsvorhaben 41 EN: Werkstoff- und fertigungstechnische Grundlagen der Herstellung und Anwendung von hoch Siliziumhaltigem Gusseisen mit Kugelgraphit. 2012. $41 \mathrm{EN}$

3. L.-E. Björkegren, K. Hamberg. 2003. Silicon alloyed ductile iron with excellent ductility and machinability. In Proceedings of the Keith Millis symposium on ductile iron, (Hilton Head Island, SC, USA 2003)

4. DIN EN 1563: Gießereiwesen-Gusseisen mit Kugelgraphit. 2012

5. P. Weiß, M. Riebisch, A. Bührig-Polaczek, Mechanical properties and impact toughness of nickel and aluminum alloyed high silicon ductile iron. Mater. Sci. Forum 925, 304-310 (2018)

6. J. Pearce. Inoculation of cast irons: practices and developments. In Thailand: National Science and Tech Development Agency, Ministry of Science and Technology, pp. 28-31 (2008)

7. S.N. Lekakh, C.R. Loper Jr., Improving Inoculation of Ductile Iron. AFS Trans. 111(05), 885-895 (2003)

8. D.M. Stefanescu, G. Alonso, P. Larrañaga, E. De La Fuente, R. Suárez, Reexamination of crystal growth theory of graphite in iron-carbon alloys. Acta Mater. 139, 109-121 (2017)

9. G. F. Goodrich. Fading in Ductile Iron Processing. Hot Topics, Ductile Iron Society, 2013(1).

10. C. Labrecque, M. Gagné, A. Javaid, M. Sahoo, Production and properties of thin-wall ductile iron castings. Int. J. Cast Met. Res. 16(1-3), 313-331 (2003)

11. S.S. Ojo, I. Riposan, Alloy selection for in mould inoculation to control chill width in ductile iron. Mater. Sci. Technol. 28(5), 576-581 (2012)

12. N. Ivan, M. Chisamera, I. Riposan, Control of graphite degeneration in the surface layer of $\mathrm{Mg}$-treated iron castings in resin sand-P-toluol sulphonic acid (PTSA) molds. Trans. Am. Foundrym. Soc. 121, 379-390 (2013)

13. A. Kutz, P. Martin, A. Bührig-Polaczek. 2018. Microstructural adjustment of the degenerated graphite layer in ductile iron for targeted evaluation on the fatigue properties. In Proceedings of the Keith Millis symposium on ductile iron, (Hilton Head Island, SC, USA 2018)

14. N. Ivan, M. Chisamera, I. Riposan, Mold coatings to reduce graphite degeneration in the surface layer of ductile iron castings. Int. J. Metalcast. 6(4), 61-70 (2012)

15. S. Boonme, D.M. Stefanescu, Casting skin management in compacted graphite iron part I: effect of mold coating and section thickness. Trans. Am. Foundrym. Soc. 121, 435-448 (2013) 
16. J. Qing, S. Lekakh, V. Richards, No-bake S-containing mold-DI metal interactions: consequences and potential application. Trans. Am. Foundrym. Soc. 121, 409-418 (2013)

17. S.F. Fischer, H. Groß, A. Bührig-Polaczek, M. Bünck, Surface layer inoculation of a sand cast hypoeutectic gray iron melt. J. Mater. Process. Technol. 220, 251-256 (2015)

Publisher's Note Springer Nature remains neutral with regard to jurisdictional claims in published maps and institutional affiliations. 